\title{
Reused rails for underground systems
}

\author{
Dmitry Potapov ${ }^{1, *}$, Volodymyr Vitolberg ${ }^{1}$, Danylo Shumyk ${ }^{1}$, Viacheslav Ovcharenko ${ }^{2}$, and \\ Viktor Bulgakov ${ }^{3}$ \\ ${ }^{1}$ Ukrainian State University of Railway Transport, Feierbakh Square 7, 61050, Kharkiv, Ukraine \\ ${ }^{2}$ National Academy of the National Guard of Ukraine, Defenders of Ukraine sq. 3, 61001, Kharkiv, \\ Ukraine \\ ${ }^{3}$ Utility Company "Harkovvodokanal”, st. Kontorskaya, 90, Kharkiv, Ukraine
}

\begin{abstract}
The structural components of the rail track, including rails, deteriorate in operation. However, some of them retain their operational characteristics and can be reused. This practice has found wide application on Ukrainian railways and shown a lot of self-evident advantages, among which the basic one is a rational use of material and technical means. Besides, development of a used rail system for underground railways may also optimize the track facility system for such specific conditions. The article presents results of the research into the change of the crumbling depth on the roll surface (the main rail defects of underground railways); it allowed the authors to conclude about the possibility to reuse rails for underground systems. Moreover, assessment of interacting forces in the wheel/rail system and the crumbling volume made it possible to determine rational application for used rails. The proposed system takes into account all the features of operating the railway track in underground systems, and also allows more efficient use of the residual rail resource without reducing the necessary level of traffic safety.
\end{abstract}

\section{Introduction}

A long experience in reusing materials of the permanent way on Ukrainian railways has demonstrated a lot of obvious advantages of these engineering solutions. One of the basic advantages of used materials is a more rational use of material and technical means, which has allowed optimizing the whole track facility system including the rail system. Therefore, implementation of the reused rail system for underground railways is one of the key prospective ways to provide operation of the enterprise under limited resources.

The research conducted [ $1-5]$ contributed to a considerable increase in the service life of rails due to a detailed study of defect development considering the crumbling dynamics on the rail roll surface (digital code of defect 11.1-2-3 according to [6]). Determination of main groups of defects and damages in rails during 1986-2012 contributed to safe traffic operation due to timely detection of the second group of defects (digital code of defect 21.1-2-3 according to [6]).

\footnotetext{
*Corresponding author: ppx_xiit@kart.edu.ua
} 
Therefore, in order to solve the problem to reuse $12.5-\mathrm{m}$ and $25-\mathrm{m}$ rails for underground railways the authors chose one of the Ukrainian metro systems as the basic enterprise.

The basic areas of research were:

- To determine possibility to reuse rails for main lines considering their operational peculiarities and taking into account the crumbling depth development.

- To determine groups by serviceability and fields of application for used rails by assessing interacting forces of the wheel/rail system, and considering the volume of crumbling on the roll surface.

\section{Determination of the crumbling depth on the roll surface}

The technique is based on the fundamental concepts of the reliability theory, the probability theory and the mathematical statistics. According to $[7,8]$ the failure is an event leading to full or partial inability of the object (or structural element) to function properly. Thus, all rail failures can be divided into full and partial ones in accordance with their impact on the general state of the system (the whole permanent way structure).

The most harmful rail defects (digital code of defect $21,30 \Gamma, 30 \mathrm{~B}$ ) requiring stoppage of the traffic can be considered, for example, as full failures.

The main defects (about 75\%) requiring rail removal from the metro tracks are the defects by code 11; they can be regarded as partial failures. Partial failures worsen the general serviceability of the system (as requiring a lower traffic speed) and sometimes may cause full failures.

According to [4] the deepest the crumbling is, the lower is the speed, on the condition that the rail traffic safety should be guaranteed. If the crumbling depth on the roll surface exceeds $8 \mathrm{~mm}$, the rail should be removed.

The progressive rail failure by code 11 is graphically presented in Fig.1.

Thus, four states of rail damages (I, II, III, IV) can conditionally be distinguished; they are located in the middle of the corresponding crumbling depth intervals on the roll surface. Since the passenger transportation should be provided (an established speed along the section), the rails can be replaced in any of these states.

The intensity of depth development on the corresponding intervals $\Delta t_{1}, \Delta t_{2}, \Delta t_{3}, \Delta t_{4}$, first of all, depends on the rail track layout. The lower the radius of the corresponding section of the track is, the higher is intensity in defect development.



Fig.1. Stages in development of the crumbing depth in rails by code 11 . 
According to earlier research the maximum depth, at which the rails are withdrawn, lies in a range of $2.6-6.10 \mathrm{~mm}$, i.e. for states I - III (Fig.1).

Therefore, section can serve as a reserve to increase the service life of a rail. It should be mentioned that the authors do not consider it reasonable to transcend the upper limit of the red zone as at a crumbling depth exceeding $8 \mathrm{~mm}$ it is sufficient (for underground railways) to considerably decrease the traffic speed up to $25 \mathrm{~km} / \mathrm{h}$; besides, there is a possibility for it to grow into a more harmful defect (code 11).

It should also be mentioned that the number of rails with a crumbling depth exceeding 6 mm was insignificant.

By conducting full-scale instrumental research according to the instrument ratings, all curves of one of the Ukrainian metro systems were divided into groups by radii.

And some sections were chosen for measuring the crumbling depths with an electronic digital calliper. The measurement pitch was set separately for each defect and was within a range of $15-30 \mathrm{~mm}$. Then the results obtained were processed in order to compute the average depth.

It allowed establishing that for each category the value of a random crumbling depth followed the normal distribution law.

Thus, for curves with a radius of $500 \mathrm{~m}$ and less the average crumbling depth was in a range from $2.5 \mathrm{~mm}$ to $4.25 \mathrm{~mm}$, which is an absolutely high value among all the categories of radii. The lowest value was $1.8 \mathrm{~mm}$ (for straight sections and curves of a radius exceeding $1001 \mathrm{~m}$ ). In curves of other radii the average depth changed within an approximately equal limits from 2.5 to $3.87 \mathrm{~mm}$ (for radii of 501-650 m), and from 2.65 to $4.02 \mathrm{~mm}$ (for radii of 651-800 $\mathrm{m}$ ).

On the basis of the calculation the dependencies between the average crumbling depth and the tonnage passed were obtained (Fig. 2).

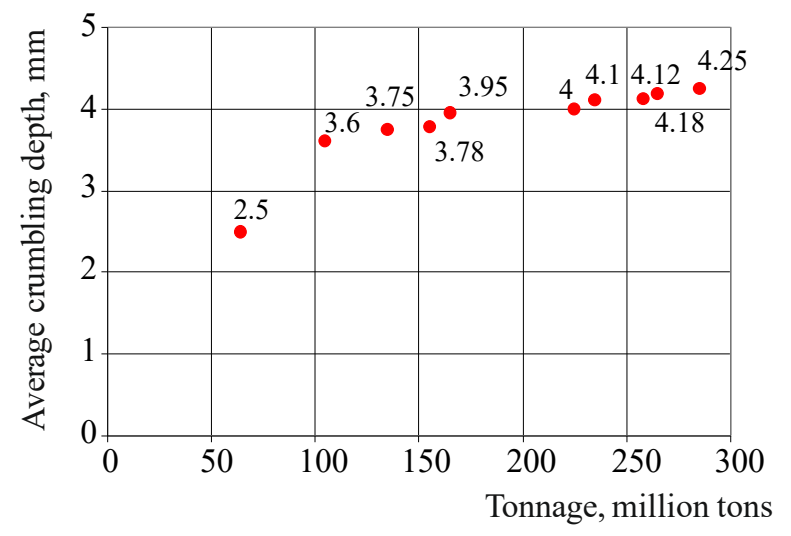

Fig. 2. Average values of crumbling depths by code 11 in curves of the radii $500 \mathrm{~m}$ and less.

It should be mentioned that the previous assumption (Fig. 1) on the nature of defect development in depth (code 11) was not absolutely right. By generalizing the results obtained, an increase in the depth can be described as follows (Fig. 3):

Three stages of the development can be conditionally distinguished. The first stage is characterized by a rapid growth of the defect's depth. It is explained by mashing the surface layers of the metal, which leads to creation of longitudinal and linear-inclined cracks in the undersurface zones; these cracks while growing encounter various stress concentrators, and, most likely, turn into transversal cracks with consequent crumbling. The undersurface microcracks can be observed as dark spots on the roll surface (Fig. 4).

In Fig. 4 the crumbling depth is within $2.56-3.3 \mathrm{~mm}$. And concentration of dark spots can be observed on both sides of the defect. 




Fig. 3. The process of the crumbling depth development by code 11 based on the calculation.

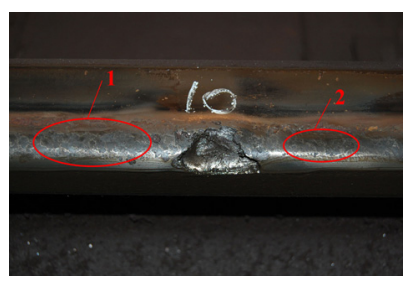

Fig.4. Dark spots on the roll surface.

The second stage is characterized by a considerable decrease in crumbling depth development (for example, in curves of the radius $500 \mathrm{~m}$ and less the depth does not virtually change within a range of $3.95-4.12 \mathrm{~mm}$ ). In addition to that, taking into account an increase in the number of microcracks in undersurface layers of the metal, the microcracks confluence with the existing ones and that leads to a greater crumbling on the roll surface (Fig. 5).

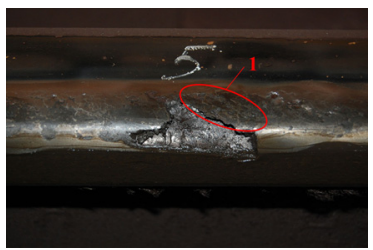

Fig.5. Growth of the crumbling area on the roll surface.

The confluence of microcracks in area 1 is clearly seen; it causes an expension of the defect area. The depth of the defect is within a range of $2.94-4.60 \mathrm{~mm}$.

At the final (third) stage irreversible processes in the metal rail head (including structural changes) run to deeper layers, thus repeatedly increasing the speed of the crumbling depth development.

The average crumbling depths obtained $(H)$ were consequently approximated in the MathCAD as follows

$$
H(t)=A_{1} \cdot t^{3}+A_{2} \cdot t^{2}+A_{3} \cdot t+B
$$

where $t$ is the tonnage passed, million tons. $A_{1}, A_{2}, A_{3}, B$ are the empirical coefficients calculated with the least-squares method. 
And on the base of the experimental data the theoretical curves to define the increase intensity of a crumbling depth was obtained. Fig. 6 gives the diagram of curves of the radii $500 \mathrm{~m}$ and less as an example.



Fig. 6. Approximation of crumbling depths by code 11 in the radii $500 \mathrm{~m}$ and less.

\section{Determination of crumbling volumes}

While planning the rail observation procedure, the authors selected track sections with the tonnage $\left(T_{\text {ton }}\right)$ close to the normative $\left(T_{\text {norm }}\right)$, in order to more accurately assess the geometry of rail defects in the pre-critical state.

To this effect, the dimensionless coefficient $K_{\text {res }}$ was calculated:

$$
K_{\text {res }}=\frac{T_{\text {ton }}}{T_{\text {norm }}}
$$

where $T_{\text {ton }}$-value of tonnage passed along the section, million ton; $T_{\text {norm }}$ - normative tonnage, million tons.

According to the requirement $0.6 \leq K_{\text {res }} \leq 1$ the sections for observation were chosen.

During the observation the basic geometry (length, width, depth) of the crumbling on the roll surface was measured with the caliper and the crumbling areas exceeding $25 \mathrm{~mm}$ in length were taken into considerations.

The measurement pitch of a depth for each crumbling zone was separately established and depended on the length and width.

The following parameters were calculated for each testing section:

$\bar{L}$ is the average length of the crumbling areas, mm;

$\bar{A}$ is the average width of the crumbling areas, mm;

$\bar{h}$ is the average depth of the crumbling areas, $\mathrm{mm}$.

Besides, the maximum crumbling depth $h_{\max }$ was established. 
The volume of each crumbling $(V)$ was calculated on the basis of its outline by one of the variants (in some cases several variants were applied simultaneously): layer segment, half of the oblate spheroid, paraboloid and spherical sphere [9].

The total volume of crumbling $\left(V_{\text {total }}\right)$ for a specified testing section was calculated as:

$$
V_{\text {total }}=\sum_{i=1}^{N} V_{i}
$$

where $V_{i}$ - volume of the corresponding crumbling, $\mathrm{mm}^{3} ; N$ - total number of crumbling areas along the testing section.

The authors believe that as far as the number of testing sections for certain radius categories was not sufficient and, moreover, several parts of the curves had already been replaced to provide the safe operation on (in some cases the whole track line, which meant that the volume of crumbling could not be assessed). Therefore, the authors decided to introduce a single factor - a specific crumbling volume $\left(V_{\text {specific. }}\right)$. It was defined as

$$
V_{\text {specific }}=\frac{V_{\text {total }}}{T_{\text {ton }} \cdot K_{\text {res }}},\left(\mathrm{mm}^{3} / \text { million tons }\right)
$$

Then the average value of it $\overline{V_{\text {specific }}}$ was calculated for each radius category.

In order to define the serviceability groups and spheres of application for used rails in underground systems the authors investigated into the action of a vehicle to the track on the base of $[10,11,12]$.

By comparing the level of acting stresses in the rail head with the admissible ones, it is recommended to use for main metro lines those used rails which were removed from all radius categories along main lines, both during complete replacement and routine maintenance procedures, with the exception of curves of the radius $500 \mathrm{~m}$ and less.

In terms of the average depth and specific crumbling volume on the roll surface, it is advisable to divide used rails into three groups by serviceability:

I group - used rails for main lines on straight sections and curves of the radius $501 \mathrm{~m}$ and more.

II group - used rails for main lines on straight sections and curves of the radius $651 \mathrm{~m}$ and more.

III group - used rails which cannot be used for main lines.

\section{Conclusions}

1. The average crumbling depth on the rail roll surface with the tonnage close to normative is in a range of $3.24-3.97 \mathrm{~mm}$.

2. The average specific crumbling volume on the rail roll surface with the tonnage close to normative is $98.92-141.15 \mathrm{~mm}^{3} /$ million tons. It increases when the radii decreases.

3. Three serviceability groups for used rails were established by the results of the research with the application of numerical methods for the action of the vehicle to the track with consideration of the average depth and specific crumbling volume on the roll surface.

\section{References}

1. E.I. Danilenko, R.M. Yosifovich, O.A. Oliynik, O.O. Soroka, Zb. nauk. prats' DETUT. Seriya «Transportni sistemi i tekhnologii», (22), 10-20 (2013) 
2. V.V. Kosarchuk, A. V. Agarkov, Zb. nauk. prats' DETUT. Seriya «Transportni sistemi i tekhnologii», (20), 77-89, (2012)

3. J.W. Ringsberg, H. Bjarnehed, A. Johansson, B.L. Josefson, Proceedings of the Institution of Mechanical Engineers, Part F: Journal of Rail and Rapid Transit, 1(214), 7-19 (2000)

4. A.Yu. Abdurashitov, Put' i putevoe khozyaystvo, 11, 16-20 (2002)

5. M.Kh. Akhmetzyanov, Vestnik VNIIZhT, 2, 36-43 (2003)

6. Classification and Catalogue of Defects and Damages in Rails on Ukrainian Railways (Kyiv, 2013)

7. M.N. Stepnov, Statisticheskie metody obrabotki rezul'tatov mekhanicheskikh ispytaniy (Moskow, 1985)

8. K.A. Braunli, Statisticheskaya teoriya i metodologiya v nauke i tekhnike (Moskow, 1977)

9. G.A. Korn, T.M. Korn, Mathematical handbook, (Moskow, 1974)

10. O.M. Darenskiy, Yu.L. Tuley, D.O. Potapov, A.S. Malishevs'ka, «Science and Transport Progress». Bulletin of Dnipropetrovsk National University of Railway Transport, 6(66), 96-104 (2016)

11. O.M. Darenskiy, A.S. Malishevs'ka, Information and control systems at railway transport, 1(122), 43-51 (2017)

12. A. Darenskiy, D. Potapov, Yu. Tuley, N. Bugaets, A. Malishevskaya, MATEC Web of Conferences, 116, 03001 (2017) 